\title{
Glasses-free 3D versus 2D video-assisted thoracoscopic thymectomy: a single-center short-term comparative study
}

\author{
Xukai Li ${ }^{1 \#}$, Fei Cui ${ }^{1 \#}$, Tuo Xing ${ }^{1}$, Ying Huang ${ }^{1}$, Jinghui Deng ${ }^{2}$, Zhexue Hao ${ }^{1}$, Jun Liu ${ }^{1}$, Jianxing He ${ }^{1}$ \\ ${ }^{1}$ Department of Thoracic Surgery and Oncology, the First Affiliated Hospital of Guangzhou Medical University, State Key Laboratory of Respiratory \\ Disease, National Clinical Research Center for Respiratory Disease, Guangzhou Institute of Respiratory Health, Guangzhou 510120, China; \\ ${ }^{2}$ Department of Clinical Medicine, The Third Clinical School of Guangzhou Medical University, Guangzhou 511436, China \\ Contributions: (I) Conception and design: All authors; (II) Administrative support: J Liu; (III) Provision of study materials or patients: J Deng, Z Hao; \\ (IV) Collection and assembly of data: X Li, T Xing; (V) Data analysis and interpretation: X Li, Y Huang, F Cui; (VI) Manuscript writing: All authors; \\ (VII) Final approval of manuscript: All authors. \\ "These authors contributed equally to this work. \\ Correspondence to: Jun Liu, MD; Jianxing He, MD. Department of Thoracic Surgery, The First Affiliated Hospital of Guangzhou Medical University, \\ 151 Yanjiang Road, Guangzhou 510120, China. Email: Liujun9707@sina.com; drjianxing.he@gmail.com.
}

Background: Thymectomy is widely used to for the treatment of thymomas, thymic cysts, thymic adenocarcinomas, and other thymic diseases. The development of video-assisted thoracoscopic surgery (VATS) thymectomy by our team offers the advantages of a glasses-free 3D thoracoscopic system for pulmonary surgery. The aim of the present retrospective study was to compare the advantages and shortterm outcomes of glasses-free 3D VATS $v$ s. 2D VATS for the treatment of thymic diseases.

Methods: The medical records of patients who underwent traditional 2D and glasses-free $3 \mathrm{D}$ videoassisted thoracoscopic thymectomy at the First Affiliated Hospital of Guangzhou Medical University from May 2015 to December 2018 were retrospectively reviewed, while focusing on the collection, evaluation, and comparison of clinical data and perioperative manifestations.

Results: A total of 152 patients were included, of which 71 patients underwent glasses-free 3D VATS and 81 underwent 2D VATS. There were no significant differences in demographic characteristics and baseline variables between the two groups $(\mathrm{P}>0.05)$. The overall surgical duration was significantly shorter in the $3 \mathrm{D}$ group than the $2 \mathrm{D}$ group $(105.08 \pm 4.08$ vs. $119.93 \pm 4.81 \mathrm{~min}$, respectively, $\mathrm{P}=0.022)$. Further intergroup comparisons revealed that the median estimated intraoperative blood loss volume $(10 \mathrm{vs} .20 \mathrm{~mL}$, respectively, $\mathrm{P}=0.038)$ was less, postoperative thoracic tube indwelling rate (43/71 vs. 64/81, respectively, $\mathrm{P}=0.013)$ was lower, and the median duration of postoperative hospitalization ( 3 vs. 4 days, respectively, $\mathrm{P}=0.034$ ) was shorter in the $3 \mathrm{D}$ group than the $2 \mathrm{D}$ group. Although no patient had died, complications occurred in $5(7.0 \%)$ patients in the $3 \mathrm{D}$ group and $9(11.1 \%)$ in the $2 \mathrm{D}$ group $(\mathrm{P}=0.387)$.

Conclusions: As compared with traditional 2D thoracoscopy, glasses-free 3D VATS thymectomy is both safe and effective, and can shorten the surgical duration, reduce blood loss, decrease the indwelling rate of thoracic tube, and shorten the postoperative length of hospitalization.

Keywords: Thymectomy; video-assisted thoracoscopic surgery (VATS); glasses-free three-dimensional thoracoscopy

Submitted Aug 23, 2019. Accepted for publication Nov 05, 2019.

doi: $10.21037 /$ atm.2019.11.96

View this article at: http://dx.doi.org/10.21037/atm.2019.11.96 


\section{Introduction}

Thymectomy is commonly applied for the treatment of thymomas, thymic cysts, thymic adenocarcinomas, and other thymic diseases, as well as to control the symptoms of myasthenia gravis (1). Along with the development of surgical technologies, methods used for thymectomy have been vastly improved. As compared with traditional median sternotomy, the invasiveness and perioperative complications of video-assisted thoracoscopic surgery (VATS) thymectomy are greatly reduced for the treatment of myasthenia gravis and anterior mediastinal tumors, while safety and practicability have been significantly improved (2). Meanwhile, VATS-related equipment has evolved from the traditional two-dimensional (2D) thoracoscope to a three-dimensional (3D) head-mounted thoracoscope with the use of glasses. Although a pair of polarized $3 \mathrm{D}$ glasses is needed to obtain stereo images, many surgeons complain of becoming tired and dizzy while wearing protracted $3 \mathrm{D}$ glasses and have reported switching between different visual channels when interacting with off-screen environments. In addition, black glasses can reduce the brightness of the screen, although exhaling creates fog, which affects the view of the screen. On May 5, 2015, glasses-free 3D thoracoscopy was applied for the first time in our center for the treatment of a patient with lung cancer (3). This method was found to safe for radical lung cancer surgery, even complex radical resection of pulmonary carcinoma (4), and can significantly shorten the duration of mediastinal lymph node dissection as compared that of $2 \mathrm{D}$ thoracoscopic surgery (5). However, for patients undergoing thymectomy, there is still no relevant report on the comparison of glasses-free $3 \mathrm{D}$ thoracoscopy with traditional 2D thoracoscopy. Therefore, the aim of the present study was to compare the outcomes of glasses-free $3 \mathrm{D}$ versus $2 \mathrm{D}$ VATS to assess the advantages of glasses-free $3 \mathrm{D}$ thoracoscopic surgery for thymectomy.

\section{Methods}

The clinical data of 152 patients who underwent thymectomy for an anterior mediastinal mass or myasthenia gravis from May 2015 to December 2018 in our center were retrieved from electronic medical records and retrospectively reviewed. Clinical data included age, sex, body mass index, maximum diameter of the thymic mass, date of surgery, surgical information, postoperative histopathologic changes, and complications. Exclusion criteria were previous median sternotomy, change to thoracotomy, and bilateral simultaneous surgery, as well as malignant cases involving peripheral organs. Of 219 patients who underwent thymectomy, 37 who underwent median sternotomy and 30 changed to thoracotomy or with invasion of surrounding tissues and organs were excluded from analysis. Finally, a total of 152 patients were included in the study, including 81 cases in the traditional 2D group and 71 in the glasses-free 3D group. The study protocol was approved by the Clinical Ethics Committee of our hospital. A research flow chart is shown in Figure 1.

\section{Principle of glasses-free 3D imaging}

The principle of glasses-free 3D imaging has been described in detail by Liu et al. (6). The glasses-free 3D system used in this study has a resolution of $1,920 \times 1,080$, brightness of $250 \mathrm{~cd} / \mathrm{m}^{2}$, and crosstalk of less than $4 \%$. Intraoperatively, a forehead-mounted circular tracker was used by the surgeon to capture real-time glasses-free 3D images (Figures 2,3). The system also consisted of two cameras at the top of the screen facing the surgeon's eyes. 3D images are acquired by a combination of a dual-channel image data system and an eye position information system, and then projected onto a glasses-free 3D screen for imaging. The biconvex lens divides each pixel of the image into several sub-pixels and subsequently projects the sub-pixels in different directions. When the surgeon concentrated on the screen, the left and right eyes receive different images superimposed by different sub-pixels owing to different angles of view of each eye. These sub-pixels generate binocular parallax of the $3 \mathrm{D}$ image, thus forming a stereo image.

\section{Surgical procedures}

Two approaches are applied in routine surgery. During VATS thymectomy with the patient in the supine position at $45^{\circ}$, three $1-\mathrm{cm}$ skin incisions were made along the front axillary line of the third intercostal space, as well as the middle axillary line of the third and sixth intercostal spaces, respectively. Selectively, incisions of 3 and $1 \mathrm{~cm}$ were made along the front axillary line of the third and intercostal spaces, respectively, or an incision of $3 \mathrm{~cm}$ along the front axillary line of the fifth intercostal space. The number of incisions was dependent on the size of the tumor and the surgeon's preferences and experience. In most cases, an incision was made from the right thoracic region adjacent to the anterior mediastinal tumor, while the left thoracic 


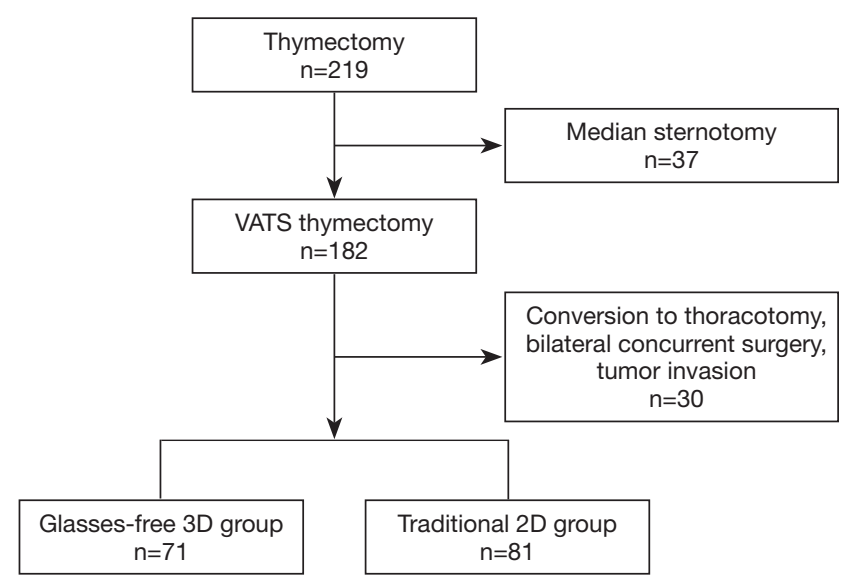

Figure 1 The study flowchart.

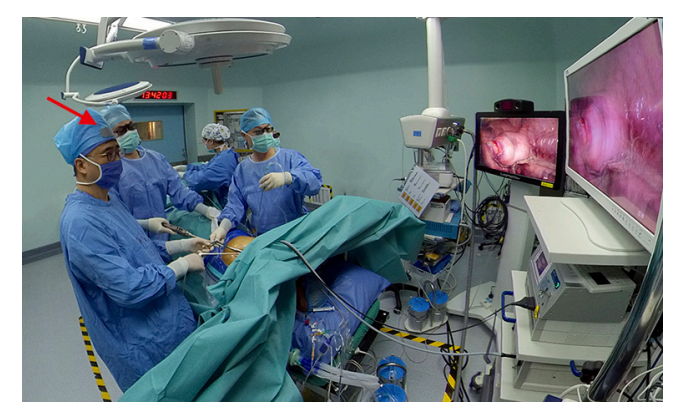

Figure 2 The surgeon had a label on the forehead (red arrow) with glasses-free 3D display system in operation, and the assistants was watching the other screen with $3 \mathrm{D}$ glasses.

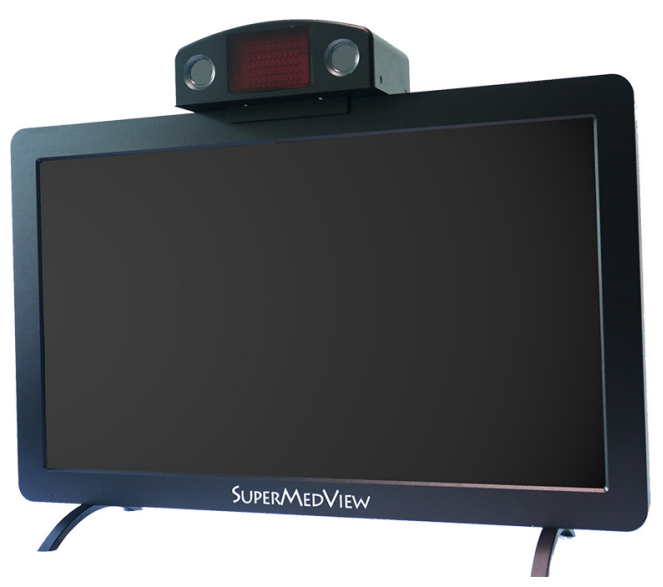

Figure 3 The glasses-free 3D display system. approach can be selected if the tumor was mainly located on the left side.

During subxiphoid VATS thymectomy, following adjustment of the patient in the supine position with the legs separated, the surgeon stands between the legs of the patient, while the assistant is responsible for holding the thoracoscope along the right side of the patient. A subxiphoid transverse incision of $3 \mathrm{~cm}$ is made, followed by a 0.5 -cm incision on each side of the rib arch $4 \mathrm{~cm}$ away from the xiphoid process, respectively. A 5-mm Trocar is inserted under the xiphoid process and a $12-\mathrm{mm}$ Trocar is then inserted under the xiphoid process, which is connected to $\mathrm{CO}_{2}$ gas at a pressure of $8 \mathrm{mmHg}$ and flow rate of $20 \mathrm{~L} / \mathrm{min}$. Then, a thoracoscope is inserted for observation.

\section{Statistical analysis}

Basic patient data, clinical variables, and pre-and postsurgical complications were recorded. Data are presented as the mean \pm standard deviation. The Student's $t$-test or non-parametric test was used to compare continuous variables between groups, while the Pearson chi-square test or Fisher's exact test was used to compare variables. A probability $(\mathrm{P})$ value of $<0.05$ was considered statistically significant. All analyses were performed using IBM SPSS Statistics for Windows, version 25.0 (IBM Corporation, Armonk, NY, USA).

\section{Results}

A total of 152 consecutive patients ( 78 males and 74 females) were enrolled in the study. The baseline characteristics of the patients in the 3D and 2D groups are listed in Table 1. The average age of patients who underwent thymectomy was 51.5 (range, 26-82) years. Of the 152 patients, 71 (46.7\%) underwent glasses-free 3D VATS thymectomy and $81(53.3 \%)$ underwent 2D VATS thymectomy. There were no significant differences in the sex ratio, age, body mass index, smoking history, history of myasthenia gravis, maximum diameter of thymic masses, number of incisions, and histological classification between the $3 \mathrm{D}$ and $2 \mathrm{D}$ groups.

The operative characteristics of all patients are listed in Table 2. There was a significant difference in the mean surgical duration between the $3 \mathrm{D}$ and $2 \mathrm{D}$ groups (105.08 \pm 4.08 vs. $119.93 \pm 4.81 \mathrm{~min}$, respectively, $\mathrm{P}=0.022)$ (Figure 4). Further intergroup comparisons revealed that as compared to the $3 \mathrm{D}$ group, in the $2 \mathrm{D}$ group, the median estimated intraoperative blood loss volume (median, 
Table 1 Baseline characteristics of patients

\begin{tabular}{|c|c|c|c|}
\hline Characteristic & $3 D$ group & 2D group & $P$ value \\
\hline $\mathrm{N}$ & 71 & 81 & - \\
\hline Age (years) & $52.08 \pm 1.46$ & $50.54 \pm 1.44$ & $0.457^{\mathrm{a}}$ \\
\hline Sex & & & $0.429^{a}$ \\
\hline Male & 34 & 44 & \\
\hline Female & 37 & 37 & $0.165^{b}$ \\
\hline BMI $\left(\mathrm{kg} / \mathrm{m}^{2}\right)$ & $23.72 \pm 3.28$ & $23.12 \pm 0.27$ & \\
\hline Smoking history & & & $0.963^{\mathrm{a}}$ \\
\hline Yes & 16 & 18 & \\
\hline None & 55 & 63 & \\
\hline$M G$ & & & $0.387^{\mathrm{a}}$ \\
\hline Yes & 15 & 22 & \\
\hline None & 56 & 59 & \\
\hline Tumor diameter (cm) & $4.80 \pm 0.22$ & $4.78 \pm 0.25$ & $0.961^{b}$ \\
\hline Incision location & & & $0.131^{\mathrm{a}}$ \\
\hline Left & 17 & 14 & \\
\hline Right & 49 & 53 & \\
\hline subxiphoid & 5 & 14 & \\
\hline Incision number & & & $0.233^{\mathrm{a}}$ \\
\hline Single & 10 & 7 & \\
\hline Two & 49 & 52 & \\
\hline Three & 12 & 22 & \\
\hline Pathology & & & $0.768^{a}$ \\
\hline Non-thymoma & 29 & 35 & \\
\hline Thymoma & 42 & 46 & \\
\hline $\begin{array}{l}\text { WHO histological type } \\
\text { (A/AB/B1-3/C/other) }\end{array}$ & $1 / 16 / 18 / 1 / 6$ & $3 / 10 / 27 / 3 / 3$ & - \\
\hline Masaoka stage (I/II) & $32 / 10$ & $36 / 10$ & $0.817^{\mathrm{a}}$ \\
\hline
\end{tabular}

20.0 vs. $10 \mathrm{~mL}$; 25th and 75th percentiles, 10.0 and 30.0 vs. 10.0 and $20.0 \mathrm{~mL}$, respectively; $\mathrm{P}=0.038$ ) (Figure 5) was reduced, postoperative indwelling rate of thoracic tube $(43 / 71$ vs. $64 / 81, \mathrm{P}=0.013)$ was lower, and the median duration of postoperative hospitalization (median, $3.0 \mathrm{vs}$. 4.0 days; 25 th and 75 th percentiles, 3.0 and 5.0 vs. 3.0 and 5.0 days, respectively; $\mathrm{P}=0.034$ ) (Figure 6) was shorter. Subgroup analysis of the patients showed no significant
Table 2 Operative characteristics of patients

\begin{tabular}{|c|c|c|c|}
\hline Variables & 3D group & 2D group & $P$ value \\
\hline $\mathrm{N}$ & 71 & 81 & - \\
\hline Anesthesia type & & & $0.33^{\mathrm{a}}$ \\
\hline NISV & 30 & 28 & \\
\hline IGA & 41 & 53 & \\
\hline Operation time (min) & $105.08 \pm 4.08$ & $119.93 \pm 4.81$ & $0.022^{b}$ \\
\hline Blood loss (mL) & $17.04 \pm 3.08$ & $34.51 \pm 6.33$ & $0.038^{c}$ \\
\hline Indwell thoracic tube & & & $0.021^{\mathrm{a}}$ \\
\hline None & 27 & 17 & \\
\hline Yes & 44 & 64 & \\
\hline POS (days) & $3.89 \pm 0.25$ & $4.73 \pm 0.34$ & $0.034^{c}$ \\
\hline Complications & 5 & 9 & $0.387^{\mathrm{a}}$ \\
\hline Pleural effusion & 1 & 3 & \\
\hline Pulmonary infection & 2 & 2 & \\
\hline Pulmonary atelectasis & 1 & 1 & \\
\hline Arrhythmia & 0 & 2 & \\
\hline MGC & 1 & 1 & \\
\hline \multicolumn{4}{|c|}{$\begin{array}{l}\text { a }, \chi^{2} \text { test; }{ }^{b} \text {, student's } t \text {-test; }{ }^{c} \text {, Mann-Whitney U test. NISV, } \\
\text { non-intubated spontaneous-ventilation; IGA, intubation } \\
\text { general anesthesia; POS, postoperative length of stay; MGC, } \\
\text { myasthenia gravis crisis. }\end{array}$} \\
\hline
\end{tabular}

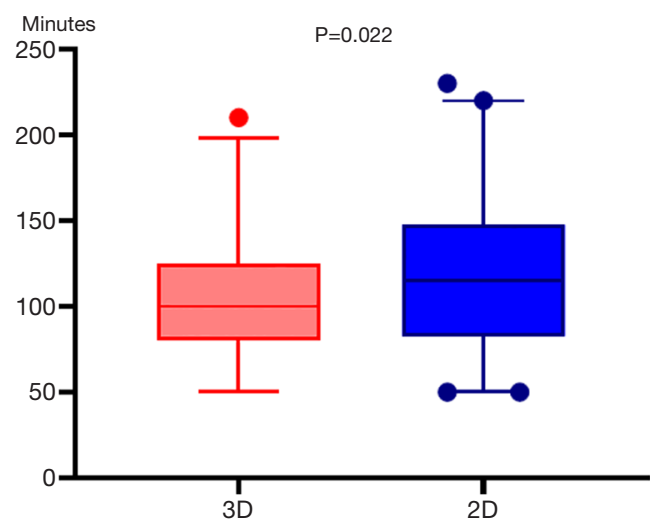

Figure 4 Operating time was significantly shorter in the 3D group than in the $2 \mathrm{D}$ group.

difference in the duration of indwelling thoracic tubes between the two groups $(\mathrm{P}=0.92)$ (Figure 7), but the total drainage volume was lower in the $3 \mathrm{D}$ group than the $2 \mathrm{D}$ group (mean, $284.4 \pm 35.56$ vs. $366.72 \pm 37.20 \mathrm{~mL}$, 


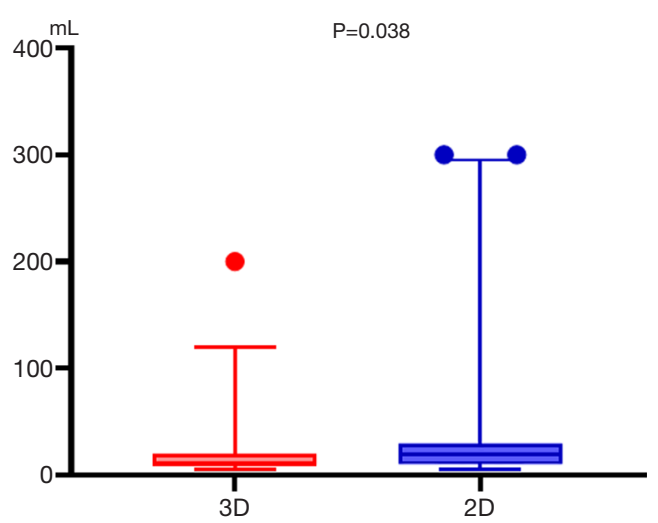

Figure 5 The estimated blood loss volume was less in the $3 \mathrm{D}$ group than in the $2 \mathrm{D}$ group.

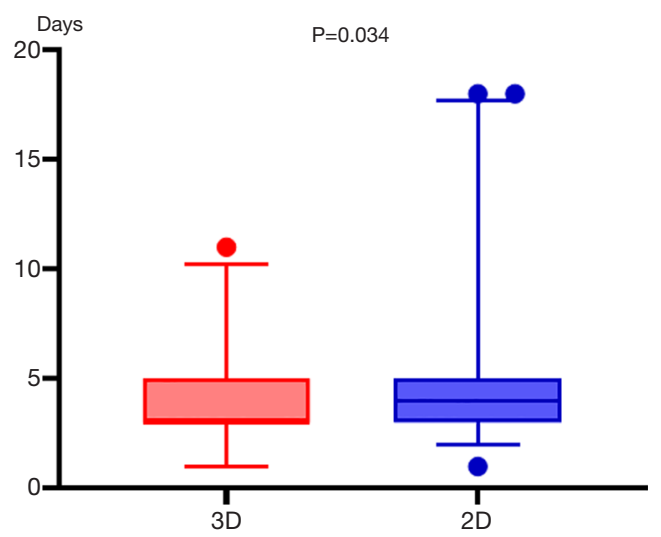

Figure 6 The postoperative length of stay was shorter in the 3D group than in the $2 \mathrm{D}$ group.

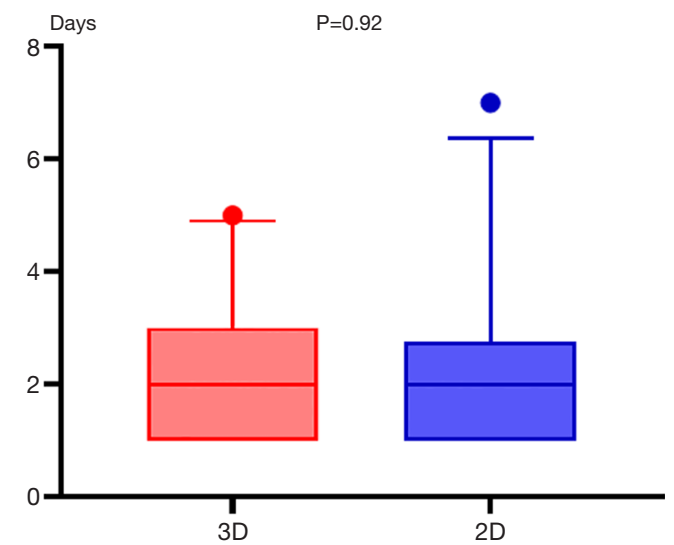

Figure 7 The days of thoracic tube drainage did not differ significantly between $3 \mathrm{D}$ and $2 \mathrm{D}$ groups.

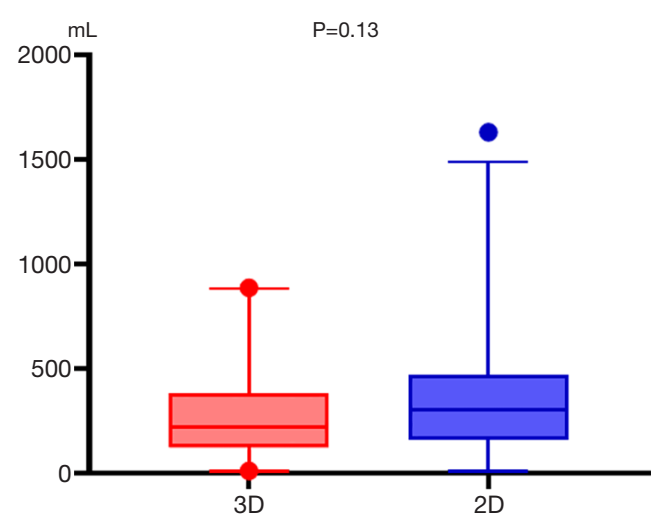

Figure 8 The total thoracic tube drainage was trend to less in the $3 \mathrm{D}$ group than in the $2 \mathrm{D}$ group.

respectively, $\mathrm{P}=0.13$ ) (Figure 8). Although no patient in either group had died, there were 14 cases of postoperative complications, which included one case of pleural effusion, two cases of pulmonary infection, one case of atelectasis, and one case of myasthenia gravis crisis in the $3 \mathrm{D}$ group, and three cases of pleural effusion, two cases of pulmonary infection, one case of atelectasis, two cases of arrhythmia, and one case of myasthenia gravis crisis in the 2D group $(9 / 81,11.1 \%)$.

\section{Discussion}

As a common thoracic disease, anterior mediastinal lesions are mostly asymptomatic, although some subjects may develop symptoms, such as shortness of breath, fatigue, panic, chest pain, and muscle weakness, among others. The appearance of symptoms is mostly related to the size and malignancy of tumors. Possible reasons may include increased compression of tumors on adjacent organs and the influence of factors secreted by malignant tumors on the endocrine system (7). Due to the poor specificity of symptoms, it is difficult to diagnose anterior mediastinal tumors in the early stage, thus an auxiliary imaging examination (chest computed tomography, magnetic resonance imaging, etc.) is needed to arrive a definite diagnosis. Surgery is the first-choice treatment for mediastinal tumors prior to medical treatment (8). The emergence of video-assisted thoracoscopy is a milestone in the era of minimally invasive surgery. At present, VATS thymectomy is widely used in clinical practice. Traditional 
$2 \mathrm{D}$ thoracoscopy is widely applied clinically, as $3 \mathrm{D}$ thoracoscopy is only available in large medical centers. The 3D thoracoscopic system provides a 3D surgical field of vision, a good sense of depth, a natural visual advantage similar to open surgery, and accurate spatial positioning without visual correction. Also, 3D thoracoscopy greatly improves the hand-eye coordination of the operator, thus reducing the difficulty of surgery and shortening the learning curve, as compared to that of 2D thoracoscopy. The surgeons wear $3 \mathrm{D}$ polarized glasses to observe $3 \mathrm{D}$ surgical images. An agreement regarding the understanding of the anatomical level and position of the operation can be reached. The advantages of 3D thoracoscopy are obviously superior to those of $2 \mathrm{D}$ thoracoscopy, which can only provide a planar field of vision. However, wearing 3D glasses for a prolonged period is prone to generate fatigue, especially during thymic surgery close to the pericardium and aorta, as the field of vision moves frequently with the beating of the heart, which is reported to promote dizziness, resulting in operational errors, bleeding, and nerve injury. Notably, glasses-free 3D thoracoscopy can restore natural stereo vision and depth perception of the actual thoracic structures, and can better visualize the tissues, blood vessels, and nerves, thereby improving the precision and efficiency of thymectomy. Also, glasses-free 3D thoracoscopy results in less intraoperative bleeding and lower indwelling rate of the thoracic tube, while up to $62 \%$ of patients are discharged within 3 days after surgery. In addition, with the use of glasses-free 3D thoracoscopy, the surgeon can complete 3-4 thoracoscopic procedures within one day. Glasses-free 3D technology is an innovation in thoracic surgery that is still in the early stages of development, but is expected to be widely applied in minimally invasive surgery in the near future (9).

In addition to the two surgical approaches described above, minimally invasive transcervical thymectomy (10) is also available, but is rarely used in our center due to the narrow surgical field. Suda et al. compared subxiphoid single-port thymectomy with VATS thymectomy, but found no significant difference in the surgical duration between the two methods (11) due to the reduced number of ports. Xie et al. found no significant difference in the surgical duration of left $v s$. right VATS thymectomy (12). Jiang et al. compared autonomous respiratory intravenous anesthesia with tracheal intubation under general anesthesia for patients with myasthenia gravis undergoing VATS thymectomy (13), and found no significant difference in the surgical duration between the two groups, indicating that the choice of the anesthetic method had no effect on the surgical process. Therefore, glasses-free $3 \mathrm{D}$ thoracoscopy is superior to $2 \mathrm{D}$ thoracoscopy in minimally invasive surgery, due to a clearer field of vision and precise removal of the thymus, which results in less bleeding and faster recovery.

The limitations to this study included the single-center, non-randomized, and retrospective nature. Moreover, there was no comparison between glasses-free 3D and traditional 3D thoracoscopy, and the comfort of glasses-free 3D thoracoscopy was not studied in depth. Hence, a largescale prospective randomized controlled study is needed to verify the comfort of glasses-free $3 \mathrm{D}$ thoracoscopy. Among 25 surgical residents, He et al. reported that the fluency and comfort of glasses-free 3D were superior to traditional 3D thoracoscopy (14). In a study of suturing of the porcine trachea, Liu et al. found that surgeons reported greater eye fatigue with traditional 3D vs. glasses-free 3D or $2 \mathrm{D}$ thoracoscopy (15). We believe that more surgeons will prefer glasses-free 3D thoracoscopy. In addition, for the glasses-free 3D system currently in use, besides the operating surgeon, the assistants still need to wear glasses to observe the screen. At present, we are also committed to the development of a multi-angle, high-resolution, glasses-free, 3D system, so that all surgical team members can obtain the $3 \mathrm{D}$ images without the use of glasses.

\section{Conclusions}

As compared with traditional 2D approaches, glasses-free 3D VATS thymectomy had several advantages, including reduced surgical duration, lower blood loss, and shortened length of hospital stay. Hence, further research in clinical practice is warranted.

\section{Acknowledgments}

Funding: This work was supported by the Science and Technology Planning Project of Guangdong Province, China (grant No. 2014A020215037).

\section{Footnote}

Conflicts of Interest: The authors have no conflicts of interest to declare.

Ethical Statement: The authors are accountable for all aspects of the work in ensuring that questions related to the accuracy or integrity of any part of the work are 
appropriately investigated and resolved. The study protocol was approved by the Clinical Ethics Committee of the First Affiliated Hospital of Guangzhou Medical University.

\section{References}

1. Voulaz E, Veronesi G, Infante M, et al. Radical thymectomy versus conservative thymomectomy in the surgical treatment of thymic malignancies. J Thorac Dis 2018;10:4127-36.

2. Lu Q, Zhao J, Wang J, et al. Subxiphoid and subcostal arch "Three ports" thoracoscopic extended thymectomy for myasthenia gravis. J Thorac Dis 2018;10:1711-20.

3. Li M. The world's first radical resection for lung cancer using glasses-free 3D thoracoscope was completed in Guangzhou. J Thorac Dis 2015;7:E384-5.

4. Shao W, Yin W, Wang W, et al. Glasses-free threedimensional endoscopic bronchoplasty, arterioplasty, and angioplasty of the superior vena cava for the radical treatment of right middle upper lung cancer. J Thorac Dis 2016;8:608-11.

5. Huang W, Liu J, Liang W, et al. Outcome and Safety of Radical Resection in Non-Small Cell Lung Cancer Patients via Glasses-Free 3-Dimensional Video-Assisted Thoracoscope Versus 2-Dimensional Video-Assisted Thoracoscope. Surg Innov 2018;25:121-7.

6. Liu J, Cui F, Li J, et al. Development and clinical applications of glasses-free three-dimensional (3D) display technology for thoracoscopic surgery. Ann Transl Med 2018;6:214.

7. Uchiyama A, Shimizu S, Murai H, et al. Infrasternal mediastinoscopic surgery for anterior mediastinal masses.

Cite this article as: Li X, Cui F, Xing T, Huang Y, Deng J, Hao Z, Liu J, He J. Glasses-free 3D versus 2D videoassisted thoracoscopic thymectomy: a single-center shortterm comparative study. Ann Transl Med 2019;7(23):761. doi: 10.21037/atm.2019.11.96
Surg Endosc 2004;18:843-6.

8. Toker A, Erus S, Ozkan B, et al. Does a relationship exist between the number of thoracoscopic thymectomies performed and the learning curve for thoracoscopic resection of thymoma in patients with myasthenia gravis? Interact Cardiovasc Thorac Surg 2011;12:152-5.

9. $\mathrm{Ng} \mathrm{CSH}, \mathrm{He} \mathrm{JX}$, Rocco G. Innovations and technologies in thoracic surgery. Eur J Cardiothorac Surg 2017;52:203-5.

10. Migliore M, Criscione A, Nardini M, et al. Single incision extended video assisted transcervical thymectomy. J Vis Surg 2017;3:154.

11. Suda T, Hachimaru A, Tochii D, et al. Video-assisted thoracoscopic thymectomy versus subxiphoid single-port thymectomy: initial results†. Eur J Cardiothorac Surg 2016;49 Suppl 1:i54-8.

12. Xie X, Gan X, Chen B, et al. Left- and right-sided videoassisted thoracoscopic thymectomy exhibit similar effects on myasthenia gravis. J Thorac Dis 2016;8:124-32.

13. Jiang L, Depypere L, Rocco G, et al. Spontaneous ventilation thoracoscopic thymectomy without muscle relaxant for myasthenia gravis: Comparison with "standard" thoracoscopic thymectomy. J Thorac Cardiovasc Surg 2018;155:1882-1889.e3.

14. He J, Ang KL, Hao Z, et al. The comparison between novel and traditional three-dimensional image system in thoracoscopy: glasses-less vs. glass. J Thorac Dis 2016;8:3075-80.

15. Liu J, Li J, Liang H, et al. Is the Glasses-Free 3-Dimensional Display System More Effective for Complex Video-Assisted Thoracic Surgery? A SelfControlled Study Ex Vivo. Surg Innov 2019;26:712-9. 